\title{
Salvador Rueda en El Globo (1885-1888). El aprendizaje de la prosa narrativa
}

\author{
Salvador Rueda in El Globo (1885-1888). \\ The Learning of Narrative Prose
}

\author{
María Isabel Jiménez Morales \\ Universidad de Málaga \\ jimor@uma.es \\ ORCID iD: http://orcid.org/0000-0002-4189-1896
}

\section{RESUMEN}

Este artículo estudia el vínculo literario entre Salvador Rueda y El Globo, importante diario madrileño con el que mantendrá una estrecha relación entre agosto de 1885 y marzo de 1888 . En él se establece cuándo y cómo entró a formar parte de su redacción, acabando con algunas inexactitudes extendidas entre los críticos. En El Globo, el autor malagueño -hasta entonces conocido solo como poeta- publicó más de un centenar y medio de crónicas periodísticas, cartas y, sobre todo: cuentos, artículos de costumbres y estampas líricas, que supusieron su aprendizaje de la prosa narrativa. Algo más del centenar de estos textos los agrupó Rueda en sus volúmenes de prosa breve, publicados entre 1886 y 1893; pero una tercera parte de ellos quedaron olvidados en las páginas de El Globo. Este artículo se ocupa, por un lado, del proceso de transmisión de los primeros artículos y, por otro, se centra en el análisis del segundo grupo de textos, hasta el momento sin investigar, complementando los estudios que actualmente se han llevado a cabo y contribuyendo al mejor conocimiento de la obra en prosa del escritor malagueño.

Palabras Clave: Salvador Rueda; El Globo; relatos y artículos de costumbres; El patio andaluz; El cielo alegre; Bajo la parra; Granada y Sevilla; Tanda de valses; Sinfonía callejera.

\section{ABSTRACT}

This article studies the literary link between Salvador Rueda and El Globo, an important Madrid's newspaper whom he will establish a close relationship between august 1885 and march 1888. It sets when and how he joined the redaction, ending with some inaccuracies extended between the critics. In El Globo, the author -until then known only as a poet- published more than one hundred and a half journalistic's chronicles, letters, tales, customs' articles..., which meant his learning of narrative prose. Rueda grouped more than a hundred of texts into different volumes of brief prose, published between 1886 and 1893; however a third of them were forgotten in the pages of El Globo. This article is responsible, on the other hand, of the transmission process of the first articles and, on the other hand, it is focused in the analysis of the second group 
of texts, that aren't investigated, complementing the studies that have been done nowadays and contributing to a better understanding of the writer's work in prose.

Key words: Salvador Rueda; El Globo; Tales and Customs' articles; El patio andaluz; El cielo alegre; Bajo la parra; Granada y Sevilla; Tanda de valses; Sinfonía callejera.

Salvador Rueda llega a Madrid en torno a 1882. En apenas tres años, consolida su actividad literaria: colabora en diversos medios - La Época, El Imparcial, La Ilustración Española y Americana, La Iberia, La Diana, La Moda Elegante, La América, Madrid Cómico, etc.- y publica cuatro nuevas obras -Noventa estrofas, Cuadros de Andalucía, D. Ramiro y Poema nacional-, que se unen a Renglones cortos y Dos poesías, dadas a la luz en Málaga, en 1880 y 1881, respectivamente. Su popularidad va en aumento, el Ateneo le abre sus puertas en abril de 1884, la prensa lo juzga con benevolencia, frecuenta a importantes escritores y recita sus versos en reuniones y salones: «más vale estar de moda, que nadie se acuerde de uno», le comenta a su amigo Narciso Díaz de Escovar (Quiles Faz 1996, 67). Todas estas circunstancias, investigadas recientemente (Jiménez Morales 2019), confluyen en su nombramiento de redactor literario de El Globo, diario con el que establecerá un estrecho vínculo entre 1885 y $1888^{1}$. Esta relación literaria no solo no ha sido estudiada por los críticos; sino que, además, estos han pronunciado y repetido afirmaciones mal documentadas, que este artículo pretende esclarecer ${ }^{2}$.

Las primeras inexactitudes que ha difundido la crítica tienen que ver con el hecho de que el escritor malagueño fue redactor jefe de este periódico cuando Alfredo Vicenti lo dirigía; adelantando, asimismo, la fecha de ingreso de Salvador Rueda en el diario madrileño a 1883 (Vázquez Otero 1960, 54; Pappas 1970, 11; Prados y López 1941, 31-32 y 1967, 61). En efecto, Vicenti fue director del periódico, pero desempeñaría este cargo entre 1893 y 1896 , cuando ya el malagueño no colaboraba de forma asidua en él ${ }^{3}$. Y, por supuesto, Rueda nunca fue redactor jefe, sino un colaborador literario más del periódico, donde

${ }^{1}$ Mi trabajo nace a raíz de la valiosa información ofrecida por Cabrerizo García (2016, 720-728), la primera investigadora que ha enumerado todos los textos que Rueda publicó en El Globo. Aunque la lista aportada es muy completa, mi revisión de este diario madrileño ha aumentado en casi treinta nuevos títulos los artículos del malagueño no recopilados ni citados hasta el momento por los críticos, y que detallo en el apéndice final de este trabajo.

2 Muchos críticos que han estudiado la figura de Salvador Rueda (Ruiz de Almodóvar 1891; Martínez Olmedilla 1908; Prados y López 1941 y 1967; Gil Muñiz 1957; Vázquez Otero 1960; Isado Jiménez 1992) no aportan datos precisos de estos primeros años de Salvador Rueda, como veremos a continuación.

3 Vid. para más información Cores Trasmonte (2009) y Alonso (2014). Este aporta interesantes datos para conocer los diferentes directores de El Globo. Sobre El Globo en general, vid. Gómez Aparicio (1971, 267-269) y Timoteo Álvarez (1981, 269-279). 
ingresó, no en 1883 -como se ha venido repitiendo-, sino dos años después, tal y como muestra una noticia de El Globo del 9 de agosto de $1885^{4}$. En ella se anunciaba la venta del diario a D. Eleuterio Maisonnave, quien fuera varias veces ministro durante la I República, y se detallaba el nuevo equipo de dirección y el elenco completo de redactores. Entre estos últimos se encontraban Alfredo Vicenti, Antonio del Val, Antonio Aura Boronal, Federico Vicent, Joaquín Mazas, Manuel Matoses, Manuel Ramos, Manuel Antón y Ferrándiz, José Almendra Morales, Salvador Rueda, Carlos Sampedro y Manuel Gutiérrez Jiménez. El director era, a la sazón, Pedro José Moreno Rodríguez, consejero de Castelar, y el redactor jefe: Manuel Troyano.

Antes de ocupar su puesto de redactor en El Globo, Rueda trabajó en sus oficinas, desde marzo o abril de 1883, desempeñando diversas tareas burocráticas, que debió simultanear con su destino en el Ministerio de la Gobernación para sacar un dinero extra a fin de mes $^{5}$. Lo confirma una breve misiva donde Rueda da la bienvenida a N. Díaz de Escovar, que recala en la corte. Como tiene muchas ocupaciones, se disculpa por no haber podido verle aún y le promete que buscará la ocasión. Pero lo que confunde al lector es la siguiente afirmación: «Esta noche fui a la redacción de El Globo y me encontré con tu tarjeta. A ver si combinamos y tenemos un rato, para que me des noticias de por allí» (Quiles Faz 1996, 63). Los estudiosos de Rueda debieron creer que ese trabajo en El Globo era el de redactor, pero tiene relación con su desempeño de oficinista, hipótesis que confirma un artículo de Antonio Cortón (1910) publicado años después en El Heraldo de Madrid. Al rememorar la figura de Alfredo Vicenti, Cortón alude a Salvador Rueda y menciona su vinculación con El Globo. Cuando la redacción de este periódico se encontraba en la calle de San Agustín, esquina con la de El Prado, Cortón solía ver pasar a sus periodistas al atardecer. Entre ellos recuerda a Salvador Rueda, que es descrito con brevedad: acompañando siempre a Joaquín Mazas, a quien solía escuchar, abstraído y silencioso. A. Cortón explica que el malagueño primero estuvo «empleado en la administración»: era «poeta feliz, con quince duros para él solo», pero sus dotes de artista y la óptima relación que mantenía con Vicenti y Troyano favorecieron su posterior ingreso en la redacción del diario, apartándolo de las tareas administrativas que desempeñaba hasta entonces: «Aquellos dos hombres [Vicenti y Troyano] crearon a Rueda, quien se les reveló por La pa-

${ }^{4}$ Idéntico anuncio se repite en este mismo diario al día siguiente. También aparece esta información en La Época, en la sección de «Noticias generales» (10-agosto-1885, p. 3).

${ }_{5}$ Es muy interesante la reproducción de la hoja de servicios del poeta, localizada en el Archivo del Ministerio de Educación Nacional (Tamayo 1943, 31-33; Pappas 1970, 32-34). Pero, hasta el momento, la información más completa y exhaustiva de los puestos administrativos que desempeñó Salvador Rueda en Madrid puede encontrarse en la Cronología de Salvador Rueda (Salvador Rueda en el contexto de su época) (Jiménez Morales y Quiles Faz 2013). Este apartado concreto ha sido elaborado por la Dra. Quiles Faz. 
rranda, que fue su primer trabajo en prosa ${ }^{6}$; le sacaron de la Administración, donde ponía fajas a los números que se enviaban a provincias, llevándole a la redacción» (Cortón 1910).

Poco a poco, Manuel Troyano fue delegando en Vicenti «la dirección del alto espíritu literario de Rueda». Esta es la razón por la que el malagueño confiesa años después que fue el escritor santiagués -y no otro- quien le enseñó «a escribir prosa» (Ruiz de Almodóvar 1891, 16) ${ }^{7}$.

\section{Las colaboraciones de Salvador Rueda en $E_{L} G L O B O$}

Cuando Rueda entra a formar parte de El Globo, este era un importante diario de carácter liberal, donde colaboraban destacados escritores del momento. A juicio de la crítica, en la década de los 80 compartía con El Liberal el tercer puesto en difusión de la prensa española, detrás de El Imparcial y La Correspondencia de España (Castillo 1975, 193). Bajo la protección de Maisonnave, llega a ser uno de los «periódicos republicanos y anticlericales de mayor difusión» del país (Gómez Aparicio 1971, 269). En los años en que Salvador Rueda colaboró en el diario, su estructura diaria podía variar puntualmente, atendiendo a la actualidad política, a la inauguración del año legislativo, a los discursos de Castelar... En esos casos, las cuatro páginas de cada número aumentaban a seis. Según rezaba su subtítulo, El Globo era un diario «ilustrado, científico y literario». Antes de formar parte el malagueño de su redacción, las colaboraciones literarias eran esporádicas. Este diario era, sobre todo, una publicación de carácter político y noticiero, con secciones fijas de crónicas parlamentarias, ecos políticos, noticias generales..., que recogía mucha información facilitada por la Agencia Fabra. Casi todos los artículos aparecían sin firma o, a lo sumo, con iniciales y seudónimos. Paulatinamente, se hizo más literario y erudito, al ofrecer un artículo diario sobre estos temas. Normalmente, solía aparecer en primera plana -espacio antes ocupado por la política-, o todo lo más, entre la primera y la segunda páginas del periódico, entre las secciones tituladas «Nuestro Grabado» y «Cosas de Todas Partes». Salvador

${ }^{6}$ La escena costumbrista que menciona A. Cortón: «La parranda» no fue su primer trabajo en prosa: ni de los publicados en El Globo -fue una estampa lírica titulada «El fuego»-, ni en el resto de periódicos madrileños, cuyo primer trabajo es «El copo y la moraga» (aparecido en El Imparcial el 18 de agosto de 1884). Sí fue, no obstante, uno de sus primeros textos, pues apareció el 19 de octubre de 1885 en El Globo, siendo su tercera entrega en el diario. «La parranda» la publicó antes en La Moda Elegante el 14 de marzo de 1885.

${ }^{7}$ Vicenti no solo protegió y enseñó a Salvador Rueda, fue mentor también de Joaquín Mazas, Pedro de Répide, Carlos Miranda y Sofía Casanova, entre otros. Con respecto a su tutela sobre el malagueño, Ruiz de Almodóvar comenta lo siguiente: «Mucho le habrá valido tal maestro, pero mucho le habrá también influido el sentimiento innato de la forma en el poeta aleccionado [...] y además el buscar su inspiración en la naturaleza» $(1891,16)$. 
Rueda tuvo mucho que ver en esa transformación, pues fue uno de los más asiduos colaboradores literarios de aquellos años. Alternaba sus trabajos con los de Joaquín Mazas, Alfonso Pérez Nieva, Andrés Corzuelo, Ginés Arrebola, Dámaso Delgado López, Mariano P. Sebiñez, Santiago Astor y, más esporádicamente, con los de Pardo Bazán, Felipe Trigo, etc ${ }^{8}$.

La contribución de Salvador Rueda en El Globo resulta sumamente relevante en su trayectoria literaria. No solo significa otro medio de subsistencia mientras se abre camino en Madrid: este diario le brinda la ocasión de poder consolidar su renombre literario. De hecho, es el medio donde más asiduamente publica el escritor malagueño entre 1885 y $1888^{9}$; y, además, en El Globo evoluciona hacia la narración en prosa, pues, hasta el momento, sus colaboraciones en prensa habían sido casi exclusivamente poemas. En las páginas de este diario madrileño, y durante dos años y medio, publica más de un centenar y medio de textos en prosa -concretamente, 157-. En colaboraciones semanales, o todo lo más quincenales, cultiva con dedicación especial cuentos y cuadros de costumbres; pero también crónicas de viaje, cartas y algún texto de crítica literaria. El propio Rueda, sin embargo, con el transcurrir de los años solo recordaría su faceta costumbrista: «Enseguida entré en El Globo; allí escribí cuadros de costumbres andaluzas, en prosa» (El Caballero Audaz 1918, 8). Son inexactas las afirmaciones de algunos críticos que insisten en mantener su imagen de poeta en El Globo (Cuevas 1986, XXVIII). Es más, en los años en que Rueda trabaja en él, este diario no publica ninguna colaboración poética de sus redactores. Los únicos versos que acogen sus páginas son los de algunas crónicas taurinas de Un Alguacil, quien, esporádicamente, volcaba su humor en el molde poético.

El escritor malagueño solía firmar sus trabajos con la inicial de su nombre seguida del primer apellido: «S. Rueda». Solo en los tres últimos artículos, publicados a partir del 28 de febrero de 1888, cambia su firma, adoptando la forma que después será habitual en él: el nombre y primer apellido completos. Pero utilizó puntualmente otras rúbricas. Con una escueta «R.» firma su cuento «Gabriel», cuya autoría puede atribuírsele sin ninguna duda, pues lo vuelve a publicar -esta vez con nombre y apellido completos- en La Ilustración Ibérica el 3 de enero de 1891, aunque con título modificado: «Una limosna para los niños». Con su primer apellido - «Rueda»- aparece la segunda de las crónicas que dedica el 25 de octubre de 1887 a su estancia en Granada, con motivo de la reconstrucción de Santa Cruz del Comercio: «El viaje a Granada»; y con sus iniciales «S. R.», firma otra crónica: «La Exposición de Horticultura», publicada el 6 de junio de 1887.

Me gustaría resaltar una peculiaridad de alguno de sus artículos de El Globo: la indicación del lugar y la fecha en que son redactados. Estas aclaraciones

\footnotetext{
${ }^{8}$ Freire (2015) ha estudiado la colaboración de la escritora gallega en este diario.

9 Ossorio y Bernard $(1908,399)$ incluye a Salvador Rueda en su célebre catálogo, pero sorprende que no cite su amplia colaboración en El Globo.
} 
se dan, principalmente, en los textos publicados a lo largo de 1885 y 1886 , apareciendo de forma esporádica, en otros trabajos suyos de 1887, en concreto los escritos a raíz de un viaje, como los que describen literariamente su visita a una bodega jerezana -«Visiones de la borrachera»-, la Semana Santa y la feria de abril de Sevilla o las primeras crónicas de su viaje a Granada. Son más interesantes las indicaciones de la fecha de composición. A veces, solo apunta el mes y el año: «agosto del 85», por ejemplo; pero son más numerosas las ocasiones en que detalla el día, mes y año concretos de escritura. Cuando esto sucede, no suelen transcurrir más de dos días entre la fecha de redacción y su publicación en el diario («La venta del pescado», «Cuadro bohemio», «El brasero», «Una casilla en la feria»... son algunos ejemplos). Siendo habitual que Rueda escriba el artículo en una fecha y se publique justo al día siguiente («El titiritero», «La feria del pueblo», «El Invernal», «Paisaje»...). También hay textos -aunque no sea lo usual- en que el lapso es cercano a la semana ( $\ll \mathrm{Se}$ aguó la fiesta», «Visiones de la borrachera», «Episodio sevillano», «La fiesta de San Antón»...). Ninguno de los artículos publicados en El Globo apareció con indicaciones, al pie del mismo, de formar parte de un futuro libro, ya fuese de cuentos o novelas. Y solo uno de ellos presenta una dedicatoria: «Desde la Giralda», concretamente a José Benítez.

Los numerosos artículos de Rueda que ven la luz en las páginas de $E l$ Globo pueden distribuirse en dos grupos a la hora de proceder a su estudio. El primero es el más nutrido. Lo forma poco más de un centenar de textos, que -entre 1886 y 1893 - Rueda reúne -a veces combinados con trabajos inéditos o publicados en la prensa- en sus seis volúmenes de prosa breve: El patio andaluz, El cielo alegre, Bajo la parra, Granada y Sevilla, Tanda de valses y Sinfonía callejera. Algunos de estos artículos los repite, incluso, en diferentes libros, pudiendo llegar a modificar sus títulos ${ }^{10}$. El segundo grupo lo integran cincuenta y cuatro textos - un tercio del total-, que contribuyen a darle a conocer en la prensa madrileña y a ganar su sustento diario, como los anteriores; pero que muestran la peculiaridad de haber permanecido olvidados en las páginas de $E l$ Globo, sin otro objetivo que la inmediata lectura tras su publicación.

Desconozco las razones que movieron a Salvador Rueda a seleccionar unos textos, y otros no, para reunirlos en volúmenes y sacarlos de su medio natural: el periódico. Con respecto a las crónicas de viajes publicadas en $E l$ Globo, resulta evidente que eligió las de carácter más literario y artístico para recopilarlas en Granada y Sevilla, prescindiendo de las estrictamente informativas. En relación con los cuadros de costumbres seleccionados, se pone

10 Solo lo hizo con seis artículos: «Margaritas a puercos» lo incluyó en Bajo la parra y en Tanda de valses; "Marina», en Bajo la parra y en Sinfonía callejera; «La casa de campo» vio la luz en El cielo alegre y en El gusano de luz; «El casorio», en El cielo alegre y Sinfonía callejera, y «Después del miserere» y «Una casilla en la feria» los publicó tanto en El cielo alegre como en Granada y Sevilla. 
de manifiesto que una buena parte de ellos se vinculaban temáticamente con Andalucía -sus fiestas, gentes, costumbres...-, desechando cuadros de costumbres madrileñas. Aunque también incluyó algunos de estos cuadros en sus libros, fueron menos numerosos. En cuanto a los relatos, las conjeturas resultan más difíciles de elaborar. Entiendo que Rueda seleccionó para formar parte de sus libros los textos más estimados por él, los que consideró más perfectos o mejor recibidos por los lectores. Quizá pensó, en un principio, agrupar todos sus artículos de El Globo en futuros libros, descartando esta idea cuando siguió escribiendo para otros periódicos y revistas. De hecho, los tres primeros libros recopilatorios -El patio andaluz, El cielo alegre y Bajo la parra- están integrados casi en su totalidad por artículos de este diario madrileño, proporción que disminuye en los volúmenes publicados en la década de los noventa, cuando ya había abandonado su redacción. El caso es que todos ellos produjeron un doble rendimiento literario a su autor y al seleccionarlos los puso al alcance de un público diferente al lector del periódico. Estos trabajos de Rueda han sido estudiados por la crítica (Ezama Gil 1992; Rodríguez Fischer 2008; Casas 2008; Cabrerizo García 2015 y 2016; Jiménez Morales 2016 y 2017), por ello las reflexiones que siguen tienen que ver sobre todo con su proceso de transmisión.

De los seis volúmenes misceláneos que edita el malagueño, los tres primeros ven la luz mientras colabora activamente en El Globo. El patio andaluz se publica en abril de $1886^{11}$ y se nutre casi mayoritariamente de artículos publicados en sus páginas. De sus quince artículos, catorce ven la luz en este diario en el corto intervalo de cuatro meses -entre el 19 de octubre de 1885 y el 24 de febrero de 1886-. Sus títulos son: «La parranda», «El Invernal. Cuadro flamenco», «El titiritero», «Cuadro bohemio», «El molino», «El velatorio», «El bautizo», «Nochebuena», «El brasero», «El columpio», «La fiesta de San Antón», «El lañador», «El patio andaluz»y «De piedras abajo» ${ }^{12}$. A estos catorce artículos añade un texto que había publicado en La Época el 10 de octubre de 1885 - «La matanza»- y de ese modo completa el volumen. Rueda respeta todos los títulos de estos artículos de costumbres y relatos de El Globo, menos el de «El Invernal. Cuadro flamenco», que cambia en el libro por «El café flamenco». Este primer volumen lo dedica Rueda, precisamente, a sus «compañeros de redacción de El Globo», los mismos a quienes Clarín enviaba sa-

${ }^{11}$ Así se anuncia en El Liberal, 2-abril-1886, p. 3. (Dice así la noticia: «Hoy se pone a la venta en las principales librerías un precioso libro de D. Salvador Rueda, titulado El patio andaluz».) Vid., además, El Día, 16 y 18-abril-1886 y El Liberal, 15, 17 y 19-abril-1886.

12 Sería muy prolijo repetir las fechas de publicación de todos sus artículos en El Globo, por ello remito al estudio de Cabrerizo García (2016, 720-728) y al apéndice final de este artículo. Los he citado según el orden cronológico de aparición en El Globo, como haré en todos sus textos. 
ludos y recuerdos cariñosos por intermediación del malagueño ${ }^{13}$. La crítica fue benévola con este libro. En general, resaltó muy positivamente el cambio experimentado por el autor al pasar de la poesía a la prosa: «Rueda ha dado muy airosamente el difícil salto de abajo arriba -afirmaba Mariano de Cavia- pasando de los romances descriptivos de Poema nacional a los cuadros de costumbres de El patio andaluz, libro de pocas páginas, pero de copiosas bellezas» ${ }^{14}$. Siendo de idéntica opinión un redactor anónimo de Revista de España: «¿Ha ganado, o ha perdido en el cambio? -se preguntaba el crítico- Nosotros creemos que ha ganado, porque, dadas las facultades artísticas del joven autor de El patio andaluz, la prosa es molde más amplio y favorable para vaciar sus concepciones ${ }^{15}$.

En febrero de 1887 aparece en Madrid su segundo volumen de prosa breve: El cielo alegre ${ }^{16}$. Ahora Salvador Rueda aumenta el contenido, al ofrecer al lector veinticuatro cuentos y cuadros de costumbres. Todos los había publicado antes en El Globo, en poco más de un año: de octubre de 1885 a diciembre de 1886. Tenían en común su elevada concepción lírica, que el autor había especificado en la dedicatoria, al concebir el volumen como «libro de poesías». El cielo alegre es un nuevo ejemplo de volumen recopilatorio -como lo había sido el anterior-, al nacer de la oportunidad que depara la colaboración periodística. En esta ocasión, Rueda introduce más modificaciones en el proceso: cambia el título a cinco de los artículos del diario al incluirlos en el libro ${ }^{17}$ y otros cinco trabajos de El Globo los agrupa en el volumen bajo un epígrafe aglutinador ${ }^{18}$.

${ }_{13}$ En una carta fechada el 26 de enero de 1887, Clarín solicita al malagueño que le haga llegar a sus amigos de El Globo «cariñosos recuerdos» (Rubio Jiménez y Deaño Gamallo 2014, 10). Al año siguiente -en una epístola escrita el 3 de enero del 88- repite el encargo. Esta segunda misiva fue publicada en El Globo cuatro días después como breve reseña de Clarín a Sinfonía del año (Quiles Faz 2005, 54-55; Rubio Jiménez y Deaño Gamallo 2014, 19-20).

${ }^{14}$ Cfr. «Entre paréntesis. Notas de un lector», El Liberal, 30-junio-1886, p. 1.

15 «Notas bibliográficas», Revista de España, CIX, marzo-abril-1886, p. 629.

16 Vid. los anuncios de Diario Oficial de Avisos de Madrid, 24-febrero-1887, p. 3 у Madrid Cómico, 26-febrero-1887, p. 7.

17 «En la vendimia» pasó a llamarse en el libro «La caja de pasas»; «El montón de residuos» cambió a «El montón de basura»; «La noche de luna», a «La fuente»; "Cuadro de la vendeja», a «La primera salida» y «Sol y pesetas», a «La peseta y el sol». Aparte de estos trabajos, eligió los siguientes textos del diario: «La trilla», «El casorio», «La lluvia», «Cuadro campestre», «La sombra», «Buscando nidos», «La granizada», «Tarde de junio», «El baño de los chiquillos», «El paleto de visita», «La casa de campo», «El recodo del camino», «El riego de la huerta», «La faena de naranjas», «El doctor Centurias», «El movimiento de las hojas», «Paisaje de setiembre» $\mathrm{y}$ «El palo del telégrafo».

18 «La calle de las Sierpes», «Después del Miserere. En Sevilla», «Bocetos. La noche del Jueves Santo. Las cofradías del Viernes. El Sábado de Gloria. Domingo de Pascua.- Toros», «Una casilla en la feria» y «Desde la Giralda» pasaron a titularse en el libro «Semana Santa en Sevilla». 
Me gustaría señalar que uno de sus relatos -«El recodo del camino»- lo dedica Rueda a Joaquín Mazas, entrañable compañero de redacción en El Globo.

Bajo la parra es su tercer libro de cuentos y cuadros de costumbres. Lo publica en torno a octubre de $1887^{19}$ y repite idéntica pauta que los anteriores. De sus veintinueve textos en prosa, todos se han publicado antes en El Globo, menos «La pareja de mariposas». El nuevo libro recopila textos comprendidos en un lapso más amplio que los anteriores, pues Rueda elige dos cuadros de costumbres publicados en noviembre de 1885 - «La feria del pueblo» y «La venta del pescado»-, remontándose hasta junio de 1887. Además de los dos artículos citados, elige veintiséis textos para conformar Bajo la parra en 1887, selección que sería modificada para la segunda edición de esta obra ${ }^{20}$. Por orden de aparición en El Globo, señalo los siguientes textos: «Escena al sol», «La banda de música», «Las candeladas», «El campanario», «El velonero», «Mancha»-en el libro se tituló «Crepúsculo»-, «El vaso de agua», «El musgo», «El copo» - «Los barqueros», en Bajo la parra-, «Ráfagas de otoño», «La pulga», «Bajo la parra», «Las cédulas del año», «Marina», «Salamandra», «El aguacero de oro», «Los murciélagos», «El exorcismo», «El cohete de lágrimas»-modificó su título a «El tronido»-, «Cuadro oriental», «Margaritas a puercos», «La mujer desconocida», «La burbuja», «Visiones de la borrachera», «Se aguó la fiesta» $\mathrm{y}$ «Cuadro húngaro».

Los tres libros de prosa breve que siguieron a los mencionados: Granada y Sevilla, Tanda de valses y Sinfonía callejera, aparecen en la década de los 90. Ya había abandonado Rueda la redacción de El Globo, pero estas obras seguían reuniendo textos publicados en el diario entre 1886 y 1888 . Además de cuentos y cuadros de costumbres, Rueda publica en El Globo las crónicas literarias de los viajes de aquellos años. En concreto, los efectuados a Sevilla, Granada y Murcia. Los artículos que dedica a las dos ciudades andaluzas se agrupan en un libro que publica en 1890 y que titula Granada y Sevilla. Toda la primera parte: Granada, formada por seis textos, aparece antes en el diario madrileño entre el 1 y el 27 de julio de 1887, tras su viaje a la ciudad imperial ${ }^{21}$.

19 Entre otros, he localizado anuncios de esta obra en Revista Contemporánea, octubre-1887, n. ${ }^{\circ} 68$, p. 336; El Liberal, 2-noviembre-1887, p. 3; El Día, 2-noviembre-1887, pp. 3-4; Madrid Cómico, 12-noviembre-1887, p. 7 y La Ilustración Ibérica, 26-noviembre-1887, pp. 10 y 13.

${ }^{20}$ En su edición valenciana de 1891, Rueda suprime diez textos de Bajo la parra procedentes de El Globo: «El velonero», «Visiones de la borrachera», «Ráfagas de otoño», «El campanario», «Marina», «La feria del pueblo», «Las candeladas», «Se aguó la fiesta», «Margaritas a puercos» $\mathrm{y}$ «La burbuja».

${ }_{21}$ «La noche de San Juan», «La iluminación de La Alhambra», «Desde el mirador de Lindaraja»-lo tituló en el libro «Desde el mirador de la reina»-, «Zambra de gitanos», «El Generalife» y «La Puerta del Vino». Rueda mantuvo en el volumen el mismo orden cronológico de publicación en El Globo, salvo en el caso del segundo artículo, que ubicó en el último capítulo de la primera sección de Granada y Sevilla. 
De la segunda sección del libro, compuesta por doce relatos, ocho habían visto la luz en El Globo, recogiendo impresiones de varios viajes que realizó a Sevilla en 1886 y $1887^{22}$. Rueda eligió tres artículos publicados en El Imparcial - «A Sevilla! (Desde el tren)» y «Las carreras de cintas»- y en La Ilustración Ibérica -«La procesión del Silencio»- para incluirlos en la segunda parte del nuevo volumen.

Al publicar Tanda de valses en 1891, el escritor malagueño selecciona diez artículos aparecidos en El Globo de marzo de 1887 a febrero de 1888. Resalto como curiosidad que Rueda cambiase el título a la mitad de ellos a la hora de formar parte del nuevo libro: «Margaritas a puercos», «El paso de la rondalla» -luego lo tituló «De tejas arriba»-, «La cita»-transformado en «La boda de espectros»-, «El castillo de Santiago», «La moneda fingida», «Entre paréntesis»-cambió a «A Virgilio Mattoni»-, «Danza macabra»-a «El vals de las hojas»-, «La fuga del nido», «Remember»y «Suplicada», que pasó a titular «Carta abierta». La docena de artículos restantes los elige de otras cabeceras donde colabora, destacando los publicados en El Imparcial y La Ilustración Ibérica. Me gustaría resaltar cómo en Tanda de valses se lamenta el autor del plagio sufrido en algunos relatos del libro publicados precisamente en El Globo. El cuento «La moneda fingida» (aparecido el 27 de agosto de 1887) presenta una breve nota inicial, donde Rueda denuncia, con cierta amargura, que ha visto calcado, «en la forma y en el espíritu», este relato y otros que le siguen en el volumen: «los cuales escribí para El Globo hace cuatro o seis años [...]. La advertencia no vale la pena de escribirla (lo sé), pero bueno es poner las cosas en su punto» (Rueda 1891, 79).

Dos años después, publica Sinfonía callejera, su último volumen de cuentos del siglo XIX. Con él cierra una importante etapa el autor, consciente de que -como le había aconsejado Pereda años atrás- de los libros «pura y esencialmente descriptivos no debe abusarse; pues, por bellos que sean, a la corta o a la larga, llegan a fatigar» (Sánchez Reyes 1957, 194). La mayor parte de los textos en prosa de esta obra -seis de sus diez cuentos y cuadros de costumbres- aparecen en El Globo entre el 7 de febrero de 1886 y el 22 de abril del 87. Todos, menos «Visiones de la borrachera», modifican su título al formar parte del volumen: «El casorio» pasa a llamarse «Casorio y zambra»; «La bailadora de café»»: «El zapateado»; «El esquileo del burro»: «El esquileo»; «El maestro de escuela» se titula «La escuela española»y «Marina»: «El muelle de Málaga».

${ }^{22}$ Me refiero a «Después del Miserere», «Una casilla de la feria»-transformados, respectivamente, en «El miserere» y «La feria de Sevilla»-, «En marcha. El Domingo de Ramos», «Cantos de la Pasión»-«Padrenuestros y pinceladas», en el libro-, «La cofradía de madrugada», «Desde Sevilla» y «Despedida a Sevilla». Eligió Rueda otro texto publicado en noviembre: «El pañuelo de Manila», que pasó a titularse «El mantón de Manila». 
Para concluir con esta revisión de los artículos de El Globo que Rueda reunió en otras obras creadas para la ocasión, me gustaría referirme a once de ellos que luego se convertirían en sendos capítulos de El gusano de luz: «La hora del descanso», «La casa de campo», «El desayuno», «Al rumor del agua», «Arre, burro», «Camino adelante», «La fiesta en los lagares», «Al son de la cigarra», «Pie a tierra», «La buenaventura» y «iLadrones! $»^{23}$. Vieron la luz en el diario madrileño entre mayo de 1886 y marzo de 1888. El enfoque costumbrista de estos textos y su carácter fragmentario encaja a la perfección con la entrega periodística. Salvo los dos primeros, el autor respetó sus títulos en la novela ${ }^{24}$. En una carta del 5 de mayo de 1887 , Rueda escribía a Clarín y le anunciaba que preparaba una novela -sin duda El gusano de luz-. Justificaba ante su admirado amigo la publicación de textos previos de la misma en la prensa por su exceso de ocupaciones, que le impedía darla por concluida: «voy publicando capítulos porque no puedo hacer dos trabajos a un tiempo» (Rubio Jiménez y Deaño Gamallo 2014, 55).

El segundo grupo de artículos, formado por aquellos textos de El Globo que Rueda no incluyó en sus libros, presenta un gran interés en el conjunto de su obra, pues, hasta la tesis de M. J. Cabrerizo García, la crítica desconocía por completo su existencia. El análisis que propongo no solo complementa los estudios que hasta el momento se han llevado a cabo sobre sus volúmenes recopilatorios de cuentos y cuadros de costumbres (Rodríguez Fischer 2008; Casas 2008; Cabrerizo García 2015 y 2016; Jiménez Morales 2016 y 2017), pretende ser una modesta contribución al mejor conocimiento de la obra en prosa del escritor malagueño.

Este segundo grupo de artículos está formado, principalmente, por textos narrativos, pero también lo integran un trabajo de crítica literaria y trece crónicas de viajes. «Lecturas» es el único texto crítico de Rueda en El Globo. Se abre con la opinión que el malagueño tiene de la poesía de Bécquer para, a continuación, enjuiciar la última novela de Pereda, uno de los admirados maestros de su «trinidad literaria»» ${ }^{25}$. La crónica de viajes era en aquellos años finiseculares un género a medio camino entre la información periodística y el re-

${ }^{23}$ Aparte de estos capítulos, publicó «La danza del vino»-11-septiembre-1887-, texto que, a última hora, debió desechar y no incluyó en su primera novela. Recogía a la misma protagonista -Concha-, ya enamorada de su tío Sebastián y con fuertes dudas sobre el sentimiento que albergaba su corazón. Rueda también incluyó en su novela otros capítulos aparecidos en El Imparcial y La Ilustración Ibérica. El proceso de la transmisión literaria de El gusano de luz ha sido ampliamente estudiado por Jiménez Morales (1997, 13-22 y 2008, 152-159).

24 «La hora del descanso» pasó a titularse «Las bromas campesinas»y «La casa de campo»: "La vuelta de misa». Curiosamente, ambos textos sufrieron modificaciones de diversa índole al ser incluidos en El gusano de luz.

${ }_{25}$ Por la correspondencia conservada, sabemos que Rueda escribió a Clarín una carta en la que le pedía indulgencia con la crítica de La Montálvez. El 29 de enero de 1888 le 
lato literario. En las trece crónicas que Rueda escribió para El Globo, pero no incluyó en ninguno de sus libros, no se aprecia voluntad literaria. Su autor se muestra en ellas más periodista que literato, limitándose a informar a sus lectores de lo que ve y no a interpretar sus impresiones. Este es el motivo de que simplemente las mencione y no profundice en ellas. Cinco de estas crónicas las escribió en Granada, fruto de dos viajes: uno a Alhama, en junio de 1887; y el segundo a Santa Cruz de Alhama, cuatro meses después. En ambos fue comisionado por El Globo para relatar a los lectores la reconstrucción de esos pueblos granadinos, destruidos en 1884 por el terremoto que devastó parte de Andalucía. En el primer viaje, Rueda forma parte de la comitiva que acompaña al Ministro de Fomento -el Sr. Navarro y Rodrigo-, a quien dedicará en 1890 la primera sección de Granada y Sevilla, «en recuerdo de un viaje inolvidable». A finales de octubre de 1887 visita Santa Cruz de Alhama, desde entonces conocida como Santa Cruz del Comercio, otro pueblo reconstruido por la caridad de los españoles, a iniciativa del Círculo de la Unión Mercantil de Madrid. En esta ocasión escribe tres crónicas: unas «Notas al vuelo» y dos cartas (una de ellas dirigida a Manuel Troyano). Además de estas crónicas andaluzas, Rueda escribe un artículo sobre «La Exposición de Horticultura» celebrada en el Retiro, la cual visita el autor en junio de ese mismo año; y siete textos que relatan el viaje que emprende a Murcia a finales de noviembre y primeros días de diciembre de 1887. En él informa a los lectores del periódico sobre la inauguración de las escuelas en Alcantarilla, Beniaján, Aljucer, Santiago y Zaraíche. También visita Huércal-Overa -para conocer el magnífico depósito de aguas construido por el Sr. Marín Baldo- y Cartagena, donde pasea por la ciudad y sus astilleros.

El resto de los artículos que no fueron recopilados en ninguno de sus libros se agrupa en cuadros de costumbres, cuentos y lo que Jiménez Morales definió como «estampas líricas» $(2017,77-85)^{26}$. Algunos de estos textos literarios comparten características, temas, enfoques..., o presentan peculiaridades que dificultan establecer con claridad sus límites genéricos. A grandes rasgos, puede afirmarse que hay coincidencias temáticas entre estos artículos en prosa y las poesías que, por entonces, escribe Rueda. Si comenzamos por los cuadros de costumbres, me gustaría apuntar sus títulos: «Acuarela malagueña», "Una tarde en las Ventas», «Paisaje», «El entierro de la sardina», «La procesión del Corpus. (Apunte)», «Las noches del Prado», «Tío Rodajas se muere», «Inocencio Sandez. Poeta lírico», «El puesto de romances», «El amolador de tijeras» y «El artículo diario». La materia costumbrista y la exaltación de lo regional ya había aparecido anteriormente en la obra de Rueda, en Cuadros de Andalu-

contestaba el asturiano y en su respuesta se hacían patentes los esfuerzos que le estaba costando escribir la reseña (Rubio Jiménez y Deaño Gamallo 2014, 11).

26 Asimismo, Ezama Gil (1992, 62-66) analiza el «relato lírico», con especial atención a Salvador Rueda, aunque teniendo en cuenta su producción de la década siguiente. 
cía (1883) y Poema nacional (1885) y, por supuesto, continuaría en sus libros venideros. En Cuadros de Andalucía, tres de sus cinco poemas desarrollan costumbres meridionales: «Una juerga», «El copo» $\mathrm{y}$ «A ver la novia», perspectiva geográfica que se verá ampliada en Poema nacional, pues de sus doce cantos, ahora muestra costumbres de otras regiones. Frente a la impronta andalucista del libro: fiestas, tipos, instituciones - «La boda», «La romería», «El ciego de los romances», «La fiesta andaluza» ...-, «La estudiantina» se desarrolla en Salamanca y «Una verbena» y «La fiesta nacional», en Madrid.

Esta diversificación geográfica de las costumbres que aparece en Poema nacional se aprecia en numerosos cuadros de El Globo que Rueda no recopiló en sus libros. Resulta curioso que de los doce cuadros costumbristas del diario solo cuatro fijan costumbres andaluzas - «Acuarela malagueña», «Paisaje», «Tío Rodajas se muere» y «El amolador de tijeras»-, ubicándose la mayoría en escenarios y ambientaciones madrileñas. El escritor amplía en estos textos del periódico su abanico de temas. Quizá tome conciencia de que escribe para un público al que también le complace ver su entorno retratado en la prensa que compra y lee. O la búsqueda de la variedad tal vez estuviese relacionada con su deseo de evitar ser encasillado en el costumbrismo andaluz. Sin duda, debió recordar el autor malagueño un artículo de 1885, a raíz de la publicación de Poema nacional. Costumbres populares, donde el crítico le recomendaba que estudiara «otras cosas y otras personas» (Orlando 1885, 296).

En estos cuadros de costumbres predomina el subgénero de la escena. Rueda siente debilidad por las fiestas, oficios y anécdotas de la gente del pueblo; pero también describe el esparcimiento de familias distinguidas - «Acuarela malagueña»-. Hay cuadros de costumbres de temática festiva -ya sea popular o religiosa-, que se escriben y publican conmemorando la ocasión, pudiendo calificarse, en cierto modo, de artículos de circunstancias. Pero también aborda el retrato de tipos costumbristas - curiosamente, todos urbanos-, como son la alcahueta madrileña de «El puesto de romances» y dos interesantes tipos relacionados con costumbres literarias: el poeta ridículo y pomposo de «Inocencio Sandez» y el colaborador literario del periódico en «El artículo diario». En el primero de ellos, Rueda toma partido por la poesía auténtica, sugerente, que reside y nace del sentimiento, la fantasía, los misterios y vaguedades de las cosas. El segundo texto se centra en la difícil labor del periodista -en su relato se llama Lorenzo- que desempeña «el hercúleo trabajo de escribir diariamente para el público». El autor lo retrata en el momento previo a la redacción de su artículo, carente de inspiración, «trazando mentalmente a grandes rasgos un asunto», al que no le secundan las ideas: «el asunto anda en su cabeza roto y diseminado [...] pero el trabajo hay que hacerlo; habrá que inventar un lance o cuento y salir adelante con la empresa». Esta experiencia de Lorenzo sin duda debió experimentarla el propio Rueda a lo largo de su larga e intensa colaboración con El Globo. De hecho, es más que probable que se inspirara en las oficinas del diario para describir el local donde trabaja su per- 
sonaje, repleto de esos «forzados» que mueven, en silencio, la pluma; ensimismados en su trabajo ${ }^{27}$.

En muchos de estos textos, el autor busca y persigue lo pintoresco, que ahora no solo localiza en Andalucía, sino también en Madrid, aun sabiendo que «la villa del oso anda mal en punto a paisajes», como escribirá en «Una tarde en las Ventas»; o corriendo el riesgo de decepcionarse al comprobar que la costumbre elegida ha perdido sus señas de identidad al no respetar la tradición («El entierro de la sardina»), algo impensable en las costumbres andaluzas. O que la apariencia del espectáculo importe más que la unción religiosa («La procesión del Corpus»). Como era habitual en los cuadros de costumbres, los de El Globo nacen también de su personal experiencia, tal y como constantemente confiesa el autor. Rueda está presente en su paseo por las Ventas; acude al entierro de la sardina, por el que siente gran curiosidad, acompaña de madrugada a la cuadrilla de peones que va a cavar la viña, contempla la procesión del Corpus, visita al poeta Inocencio Sandez en su gabinete... Esas experiencias supuestamente vividas obligan al autor a estar presente en el cuadro y que en primera persona se dirija al lector para explicar el tema elegido o su necesidad de salir en busca de asunto "propio para un cuadro». En estos cuadros de costumbres, ya sean rurales o urbanos, tipos o escenas, de ambientación andaluza o madrileña, predomina el lirismo por el frecuente uso de figuras literarias y la descripción impresionista, fugaz, pasajera de los diferentes tipos o escenas que retrata.

Entre los trabajos literarios de El Globo no recopilados en volúmenes por el autor, hay que mencionar un segundo grupo de trece relatos: «Cuento madrileño», «Episodio sevillano», «Torbellino», «Efecto de histerismo», «El lago misterioso», «La estrella robada», «El héroe alado», «La danza del vino», «Los zapatos de la boda», «La iniciación», «Gabriel», «El carro de duros. Cuento de Pascua» e «Incidente de un duelo». El grueso de estos trabajos apareció a lo largo de 1887. Todos muestran rasgos propios de las corrientes modernas de aquellas décadas finiseculares: acción muy breve (muchos apenas la tienen, por carecer, incluso, de diálogo), elevado componente descriptivo y fuerte lirismo, recuperación de temas como la fantasía, los sueños, el pasado medieval, la leve crítica social, la melancolía, el pesimismo... Un buen número de ellos ofrece un escenario urbano - «La estrella robada», «La iniciación», «El carro de duros», «Gabriel», «Cuento madrileño», «Episodio sevillano»-, aunque los hay que no presentan ambientación marcada - «Torbellino»-. A veces aparece una naturaleza idealizada y onírica, relacionada con lo fantástico -«El lago misterioso»- o un entorno rural - «Los zapatos de la boda», «La danza del vino» e «Incidente de un duelo»-. Casi todos los cuentos retratan costumbres contem-

${ }^{27}$ El ambiente nocturno y solitario de la redacción de un periódico ya lo había retratado en otro cuento de El Globo publicado tres meses antes (20-enero-1887): «Salamandra», cuyo protagonista también es escritor. 
poráneas, aunque «El héroe alado» presenta una ambientación medieval. Algunos relatos son intemporales, como «Torbellino», rasgo que es potenciado por su carácter alegórico.

Todos ellos presentan variedad de temas, pero, en su mayoría, son cuentos de muy escasa peripecia, como «Episodio sevillano» e «Incidente de un duelo», que apenas tienen acción. El primero refleja las bromas que se gastan dos vecinos guasones de la ciudad andaluza, mientras en el segundo se describe la caída de Juan Cumbrales en el velatorio de Peluquín, lo que provoca una incómoda carcajada entre los presentes. También puede mencionarse entre los cuentos de trama minúscula «La iniciación», donde se aborda el ritual de ingreso en una logia masónica. Similar tendencia argumental aparece en «Los zapatos de la boda» y «La danza del vino». En el primer cuento rural, Juan y Gabriela -aprendiz e hija del zapatero, respectivamente- quieren casarse, pero el padre no lo aprueba. Desean contraer matrimonio al día siguiente en la iglesia del pueblo, pero con botas nuevas, las mismas que elabora Celedonio, sin él saberlo, junto a Juan, su aprendiz. Cuando el zapatero descubre la argucia, se dirige a la iglesia y llega en el instante justo en que su hija da el sí quiero. «La danza del vino» recoge los remordimientos y preocupaciones amorosas de la protagonista: Concha, que es testigo de cómo varios zagales juegan a «los maridos», en plena época de la vendimia.

Una acción algo más desarrollada presentan tres relatos - «Efecto de histerismo», «El lago misterioso» y «La estrella robada»-, donde lo fantástico aparece estrechamente relacionado con lo onírico. En ellos, Rueda sigue las modas finiseculares que prolongaban rasgos del Romanticismo. «Efecto de histerismo» es un terrible sueño, una pesadilla de la que Ángeles Arias despierta en el preciso instante en que el relato concluye. En «El lago misterioso», el joven protagonista, prototipo del poeta solitario y melancólico, se enamora de «una abstracción sin forma y sin nombre, pero que a él le parece el símbolo de la dicha y la felicidad», que suele contemplar a orillas del lago. Una tarde se duerme y, en sueños, admira esa visión, que el autor materializa en un cuerpo femenino. En su sueño, el joven ve transformarse el lago en un suntuoso palacio consagrado a las artes. Persigue su visión, su anhelo de felicidad y cuando le va a dar alcance, despierta y todo se desvanece. El joven del lago puede entenderse como un autorretrato del autor. Al final del cuento aparece una reflexión íntima: la felicidad reside en unos labios que adora, «que sé jamás habrán de unirse para besarme». Frente a estos dos relatos, «La estrella robada» ofrece una narración en primera persona. En un derroche imaginativo, el narrador, convertido en personaje de su relato, se duerme y se transforma en diferentes objetos y animales. Anhela poder robar una estrella para regalársela a la mujer que ama (que, casualmente, no encuentra). Cuando despierta, descubre que la estrella sigue, inmóvil, en el firmamento: «Así son los sueños de la vida». 
Nuevo relato con mensaje pesimista final, donde el amor y las ilusiones se muestran inalcanzables ${ }^{28}$.

«El héroe alado» se localiza en un castillo que, defendido por Lucio Tormenta, un valiente guerrero, es atacado y asaltado por sus enemigos, de noche, cuando el protagonista duerme. Una mosca que hay en la estancia -el «héroe» del título- consigue despertarlo ante el inminente peligro, logrando repeler el ataque in extremis. Cuando Lucio se asoma a las almenas del castillo, ve brillar a lo lejos un reflejo en el aire que cree un súbito fogonazo del enemigo, pero que resulta ser el vuelo irisado del minúsculo insecto que da título al relato. Tras disparar en su dirección, la mosca muere.

Frente a la idea generalizada de Rueda como ejemplo de escritor complaciente y optimista habría que puntualizar que no pocos textos de El Globo presentan un enfoque pesimista, desengañado y trágico, que parece compartir con otros escritores del momento, como rasgo de época. Pesimistas son -como hemos visto- «El lago misterioso», «La estrella robada» y «El héroe alado»; pero debo mencionar otros cuatro relatos de enfoque similar, al que su autor ha incorporado una leve carga crítica: «Cuento madrileño», «Torbellino», «El carro de duros» y «Gabriel». Los dos primeros censuran la pérdida de valores, la amoralidad y maldad del hombre contemporáneo, lo que conlleva el rechazo de la sociedad por sus vicios (Niemeyer 1992, 74). En «Cuento madrileño», el punto de partida es desesperanzado, pues el materialismo y el vicio están a punto de vencer a la virtud, pero in extremis triunfará el bien ${ }^{29}$. Es en la gran ciudad de Madrid donde Teresa sufre el asedio de Fernando, un joven que simboliza la degeneración moral. Le hace proposiciones deshonestas, que ella está a punto de aceptar para salvar a su madre de la muerte. Se perciben claras influencias deterministas en este relato, aunque, al final, triunfa la honestidad, en una solución opuesta a la que ofrecerá años después en «Torbellino». Este es un relato alegórico, de fuerte simbología y marcado pesimismo, pues refleja la derrota del honor, la virtud, la belleza y los sentimientos puros, vencidos por la maldad y el vicio. Este mensaje altamente negativo se representa en la vertiginosa carrera de cinco corceles. En cabeza va el Amor, que es seguido muy de cerca por la Venganza, la Avaricia, la Maldad y la Lujuria, resultando este último victorioso. Recuerda en el vértigo y la rapidez de movimiento a su re-

${ }^{28}$ Rueda había tratado este tema en otros cuentos: «La mujer desconocida», «iQué raro!», «La copa de champagne» y «Remember» son algunos ejemplos. En ellos, narra un desengaño, una desilusión, un amor inalcanzable y nunca comunicado al otro. Todos estos relatos muestran la cara negativa del sentimiento amoroso, la imposibilidad de ser feliz junto al ser amado, que se convierte en tópico entre los poetas modernistas.

29 Tiene que ver este desenlace con el primer título que Rueda dio a este relato cuando lo publicó en La Moda Elegante el 6 de octubre de 1885: «Virtud a prueba». 
lato «Episodio trágico» ${ }^{30}$, y en el recurso de la alegoría a «Después del baile de máscaras. Lo que dicen los átomos de polvo», cuento que recogió en Tanda de valses, después de ser publicado en El Imparcial en febrero de1890.

Los otros dos relatos - «El carro de duros» y «Gabriel»- intensifican su mensaje desencantado si nos fijamos en sus fechas de publicación, cercanas a la Navidad. Ambos se ambientan en una gran ciudad y reflejan cierto contenido social al abordar dos asuntos espinosos. El primero: el de los quintos que movilizaban para la guerra, siempre provenientes de las clases populares, que no disponían del dinero suficiente para comprar la papeleta que les devolviese a casa; y el segundo, el de la pobreza y orfandad de tantos niños que quedaban al arbitrio de la fortuna cuando sus padres enfermaban y morían. Ambos temas son mencionados por K. Niemeyer dentro de la poesía premodernista española (1992, 74-75 y 82). A su juicio, la situación lastimosa de los que viven en la miseria se convierte en tema literario. Autores como Salvador Rueda o Manuel Reina buscan infundir en el lector una actitud de compasión por los marginados de la sociedad, con especial atención a los niños pobres y a los viejos abandonados. En estos dos relatos de Rueda, la carga emotiva es grande y presentan personajes que son hijos de madres solas que sufren por su incierto futuro. En el primero, aparece la madre que ve partir a su único hijo al frente y el tema del dolor que causa la guerra. Remigia emplea todos sus ahorros en comprar un décimo de lotería -el 724: número de quinto de su hijo- para traerlo a casa. Llega de permiso muy enfermo, para morir justo al día siguiente, en el regazo de su madre. Ese mismo día, el décimo de lotería resulta premiado. Remigia, enloquecida por la muerte del hijo y enojada con el destino, se suicida, arrojándose por una ventana. El segundo relato -«Gabriel»- narra los esfuerzos de una madre por sacar adelante a su hijo. Después de morir ella, el niño queda completamente desamparado. El trágico desenlace le sirve a Salvador Rueda para suplicar al lector una actitud compasiva y caritativa hacia esos niños que piden limosna movidos por la miseria.

Solo resta para concluir este acercamiento a los artículos que Salvador Rueda publicó en El Globo el grupo de estampas líricas que no recopiló en sus libros. Todas ellas aparecen caracterizadas por la ausencia de acción, el elevado lirismo, la paralización del tiempo y la presencia de diferentes focos espaciales. Sus títulos son los siguientes: «El fuego», «La pirámide», «Carnaval», «Monólogos vegetales. El almendro. La palmera. El ciprés», «Lo que fingen las olas», «Voces. La alondra. El canario. El ruiseñor», «La noche de viento», «Una noche en la ópera», «La tinaja», «Disminuendo», «La chimenea», «La cuerda floja. Apunte», «Recuerdos de Sevilla», «Toque de vísperas», «Apunte» y «Ave María». La temática elegida por Rueda para estos textos oscila entre la

${ }^{30}$ Este cuento apareció, primero, en La Ilustración Moderna, I, 1893, pp. 587-588. Después lo incluyó en la tercera edición de El cielo alegre (1896, 153-158). 
descripción de la naturaleza en sus diferentes aspectos, la recreación de la antigüedad clásica y la evocación de sentimientos y emociones subjetivas, pudiendo encontrarse varias de ellas en un mismo artículo.

Los dos primeros textos que publicó Salvador Rueda en El Globo aparecieron en agosto de 1885 y fueron, precisamente, dos estampas líricas: «El fuego» y «La pirámide». Sorprende que eligiera estos relatos para iniciar su colaboración literaria en este diario y no escritos de orientación costumbrista por los que ya era conocido. Quizá buscase un nuevo camino que transitar al ofrecer dos artículos fuertemente vinculados con el Modernismo, por su falta de acción, su carga erudita y lírica y su elevado exotismo. «El fuego» combina la erudición, las costumbres andaluzas y el lirismo y presenta tres diferentes escenas en que el fuego es protagonista. En todas, el goce estético de la descripción se antepone a la historia narrada. Dos de ellas son costumbristas -el cortejo de una joven en el hogar campesino y el sol abrasando los campos en época de la vendimia- y la tercera recupera el mundo grecolatino. El segundo texto: «La pirámide», recrea el antiguo e imponente Egipto, presentando un enfoque oriental del objeto seleccionado. Como en el anterior artículo, combina la erudición con el exotismo y la recreación sensorial de la arquitectura egipcia alcanza un elevado colorismo. También aborda el tema de la antigüedad clásica en «La tinaja», al describir e idealizar el objeto referido en el título con la única finalidad de producir placer estético. Estos tres relatos son una de las primeras manifestaciones en prosa de la recuperación del mundo antiguo en la obra de Salvador Rueda y muestran su temprano interés por la antigüedad. Estos textos confirman la opinión de Quiles Faz (2006, 283), quien considera 1885 el año en que la tópica grecolatina brota en la obra del malagueño en poemas «donde ya aparecen ribetes helénicos relacionados con el campo andaluz», en un intento de nacionalizar el Modernismo. Este tema lo seguiría cultivando Rueda a lo largo de toda su etapa creativa, siendo también uno de los elegidos para sus relatos y estampas líricas en prosa.

Textos como «La pirámide» o «La tinaja» se relacionan con otros del autor, donde se describe un objeto de gran poder evocador. Así aparece en «La chimenea» (no la del hogar campesino, sino la del edificio elegante en la ciudad), que le sirve para elaborar una panorámica impresionista de las chimeneas, campanarios, cables telegráficos... que se contemplan en Madrid. Es una loa a ese objeto de su biografía más íntima, que resume los encantos del hogar y una parte importante de los recuerdos del hombre. Entre sus estampas, hay textos que no describen propiamente un objeto, sino sensaciones e ideas subjetivas. Así sucede en «Disminuendo» y «Toque de vísperas». El primer relato fija en la escritura lo que está a punto de desaparecer y lo que vendrá, un instante, lo que va a morir, el paso del tiempo, el año que va a finalizar... En el segundo, a raíz del repique de unas campanas, el autor reflexiona sobre la llegada del invierno. Similar estructura presentan otros dos textos: «Apunte» y «Ave María». El primero muestra una panorámica impresionista de Madrid en un paseo 
por la ciudad tras la tormenta. El título alude al abocetamiento del relato, al carácter inacabado, al trazo apenas perfilado. En el segundo, el autor describe en primera persona una estampa sevillana donde contempla las últimas luces del crepúsculo cerca de una cruz que, al borde del camino, ruega una oración al caminante, la misma que apareció mencionada en otro texto de El Globo: «Recuerdos de Sevilla», que, de difícil adscripción genérica, ofrece la crónica autobiográfica de una accidentada excursión desde Sevilla a Alcalá del Río. Sin acción y con gran lirismo, Rueda describe el alma del paisaje, sus sonidos, sus formas y colores, su «aroma espiritual». El elemento onírico se puede ver en «Carnaval», relato en primera persona, donde el autor da rienda suelta a «los monstruos y fantasmas que hacían ronda dentro de mi cerebro» y que recuerda mucho en su concepción a otro relato del autor incluido en sus libros: «Visiones de la borrachera».

Algunas de sus estampas tienen conexión con distintos elementos de la naturaleza: las olas del mar, las aves, los árboles, el viento y sus sonidos, los insectos... Son estampas que exaltan y engrandecen el mundo natural, llegando incluso a la personificación de sus elementos. En estos textos, el lirismo es destacado, predomina la descripción, no suelen aparecer figuras humanas, salvo que esté presente el propio autor, y suelen ser textos breves. Sus títulos son: «Lo que fingen las olas», «Monólogos vegetales. El almendro. La palmera. El ciprés», «Voces. La alondra. El canario. El ruiseñor» y «La cuerda floja. Apunte». «Lo que fingen las olas» nace de los personales recuerdos del autor, tras la contemplación del mar en el atardecer, momento del día, junto a la noche, muy querido por el autor en estos textos primeros. La imaginación del poeta desborda el relato, que aúna el elemento natural (el mar y las olas), la imaginación contrapuesta a la realidad y el mundo grecolatino que aflora en sus pensamientos. La estampa con foco múltiple aparece en «Monólogos vegetales» y en «Voces». Comparten ambos textos una estructura en tres partes que Rueda cultivará en otros relatos posteriores ${ }^{31}$, la personificación del sujeto literario, el empleo del monólogo como forma narrativa y la inspiración en diferentes elementos de la naturaleza. En estos dos relatos no hay narrador y, de forma explícita, los árboles en el primer texto (el almendro, la palmera y el ciprés) y las aves del segundo (la alondra, el canario y el ruiseñor) proclaman sus cualidades y virtudes. Los árboles elegidos son un tributo al campo andaluz (el almendro), al exotismo oriental (la palmera) y a la antigüedad clásica (el ciprés), tres importantes pilares en la producción de Salvador Rueda. Relacionada con esta temática, aparece «La cuerda floja. Apunte», cuyo subtítulo nos acerca al carácter abocetado del mismo. Este bello relato es una exaltación poética más del mundo natural diminuto. El protagonista es el hilo de una te-

${ }^{31}$ Entre otros, cabe mencionar «Escena muda», que vio la luz en La Ilustración Ibéri$c a$ de Barcelona el 4 de marzo de 1893, y «El himno del fuego», publicado en Blanco y Negro (23-diciembre-1893, pp. 846-847) y en la tercera edición de El cielo alegre. 
laraña, por donde lentamente avanza un gusano, que es liberado por una mosca, hecha prisionera por la araña. El autor se centra en movimientos inapreciables, en acciones insignificantes y las enaltece.

Estas últimas estampas se relacionan estrechamente con la poesía de su etapa inicial. El tema de la naturaleza, en toda su variedad, fue cultivado por Rueda en Renglones cortos, Noventa estrofas y, especialmente, en Sinfonía del año (1888). En estos libros, el autor se interesó por todo lo minúsculo, donde, a juicio de C. Cuevas (1986, LXXVII), sorprendía el detalle más oculto de animales y plantas de insignificante apariencia. Así, en Renglones cortos y Noventa estrofas escribe «Al águila», «Sombras», «El sol», «Al mar», «El árbol naciente»...; pero también «El día», «La noche», «La mañana», «La tempestad»... Su afán «naturalista» alcanza el máximo esplendor en Sinfonía del año, una rotunda exaltación de diferentes elementos de la Naturaleza, preferentemente diminutos -la «inmersión en lo microscópico», expresión acuñada por Miguel d'Ors (1973, 32-39)-: orugas, gusanos, palmeras, tormentas, arañas, abejorros..., uniendo el deleite descriptivo a los sentimientos e ideas subjetivas que la contemplación de ese ser, entidad o fenómeno atmosférico provoca en el poeta.

$* * *$

La asidua firma de Salvador Rueda desaparece de El Globo el 17 de marzo de 1888 con «Incidente de un duelo». La salida de este diario coincide con el ingreso del escritor malagueño en otro gran periódico nacional, tal y como él mismo declara a El Caballero Audaz $(1918,8)$ : «De El Globo pasé a El Imparcial como redactor literario»y y por otros indicios de su biografía que he podido localizar ${ }^{32}$. Aunque Rueda apenas publica en El Globo después de 1888 y su presencia ya es testimonial ${ }^{33}$, este diario siguió haciéndose eco de las novedades editoriales del malagueño. Sus páginas incluían anuncios de sus obras $^{34}$ y el periódico solía informar a los lectores de las colaboraciones del

32 Así lo confirman varios hechos: una carta de Rueda del 28 de noviembre de 1888, remitida a Menéndez Pelayo, por ejemplo. En ella, el malagueño le dice al admirado maestro: «Si quiere honrarme con su contestación [se refiere a la crítica de El gusano de luz que le había solicitado], diríjala a la redacción de El Imparcial, donde estoy a sus órdenes» (Sánchez Reyes 1957, 202.) Asimismo, en las fiestas de la coronación de Zorrilla que se celebraron en Granada en junio de 1889, asistieron representantes de los más destacados periódicos españoles y extranjeros. Por El Globo es convocado Manuel Matoses, su antiguo compañero de redacción; mientras que Salvador Rueda representa en dicho evento al Ateneo de Madrid. Sin embargo, cuando asiste al banquete en honor del poeta vallisoletano, Rueda se sienta a la mesa de Zorrilla en calidad de redactor de El Imparcial (Sancho 1889, 169).

33 Según Alonso $(2014,74)$, Salvador Rueda solo publica dos poemas en Plana del Lunes, tras su época álgida en El Globo: «El golpe (soneto)» (15-marzo-1897) y «Dos sonetos» (22-marzo-1897).

34 Por ejemplo, aparece una breve reseña de En tropel (6-diciembre-1892); un anuncio de la aparición en Barcelona de El gusano de luz (19-enero-1895, p. 2); de El bloque 
malagueño en otras revistas, de los prólogos que escribía para autores noveles, de los recitales a los que era invitado... Con él cerraba una etapa importante en su producción literaria, centrada en el aprendizaje de la prosa poética y costumbrista, que le ayudaría en su posterior dedicación a la novela, género en el que se inicia justo al año siguiente con El gusano de luz.

\section{APÉNDICE BIBLIOGRÁFICO \\ Nuevas colaboraciones de Salvador Rueda en El Globo $(1885-1888)^{35}$}

-«La parranda. Cuadro de costumbres», 19 de octubre de 1885, p. 2.

-«El Invernal. Cuadro flamenco», 14 de noviembre de 1885, p. 2.

$-«$ El titiritero. Cuadro de costumbres», 18 de noviembre de 1885, p. 2.

-«Cuadro bohemio», 23 de noviembre de 1885, p. 2.

- «El molino», 7 de diciembre de 1885 , p. 2.

- «El velatorio», 14 de diciembre de 1885, p. 2.

- -El bautizo», 20 de diciembre de 1885, p. 2.

-«Nochebuena», 24 de diciembre de 1885, pp. 1-2.

- «Carnaval», 7 de marzo de 1886, pp. 1-2.

-«Cuadro campestre», 31 de marzo de 1886, p. 1.

-«Buscando nidos», 6 de mayo de 1886, p. 2.

- -Voces. La alondra. El canario. El ruiseñor», 30 de julio de 1886, p. 2.

- «La noche de viento», 13 de agosto de 1886, p. 2.

-«Inocencio Sandez. Poeta lírico», 5 de septiembre de 1886, p. 1.

-«Bajo la parra», 26 de octubre de 1886, p. 2.

-«Disminuendo», 27 de diciembre de 1886, p. 2.

-«E1 cohete de lágrimas», 21 de febrero de 1887, pp. 1-2.

-«Torbellino», 15 de julio de 1887, p. 1 .

- «La estrella robada», 10 de agosto de 1887, p. 1.

-«La cuerda floja. Apunte», 27 de septiembre de 1887, p. 1.

-«La iniciación», 10 de octubre de 1887, p. 2.

-«Recuerdos de Sevilla», 13 de octubre de 1887, p. 1.

-«El viaje a Granada. Notas al vuelo», 24 de octubre de 1887, p. 2.

$-« E 1$ viaje a Granada», 25 de octubre de 1887, p. 2.

-«El viaje a Granada. Carta última», 26 de octubre de 1887, p. 2.

- «Apunte», 15 de enero de 1888, p. 1.

-«Suplicada», 3 de febrero de 1888, p. 1.

-«iLadrones!», 7 de marzo de 1888, p. 1.

(27-abril-1896, pp. 2-3); reseñas de Fornos (2-enero-1896, p. 3), de Camafeos (12-junio-1897, p. 2) y de El césar (11-diciembre-1897, p. 3).

${ }^{35}$ Los textos que enumero a continuación no los incluye Cabrerizo García en la bibliografía de su tesis doctoral $(2016,720-728)$. Se unen, de este modo, a la valiosa aportación de la investigadora. 


\section{FUENTES}

Rueda Santos, Salvador. 1886. El patio andaluz. Cuadros de costumbres. Madrid: Manuel Rosado, Editor.

Rueda Santos, Salvador. 1887a. El cielo alegre. Escenas y tipos andaluces. Madrid: Administración de la Academia.

Rueda Santos, Salvador. 1887b. Bajo la parra. Cuadros y cuentos. Madrid: Imp. de la Gaceta Universal.

Rueda Santos, Salvador. 1890. Granada y Sevilla. Bajorrelieves. Madrid: Fuentes y Capdeville.

Rueda Santos, Salvador. 1891. Tanda de valses. Madrid: Gran Centro Editorial.

Rueda Santos, Salvador. 1893. Sinfonía callejera. Cuentos y cuadros. Madrid: Tip. de los Hijos de M. G. Hernández.

Rueda Santos, Salvador. 1896. El cielo alegre. Valencia: Pascual Aguilar, Editor.

\section{BiBLIOGRAFÍA CITADA}

Alonso, Cecilio. 2014. «Noticia de Plana del Lunes, suplemento literario de El Globo (18971898)». Anales de Literatura Española 26: 43-80.

Cabrerizo García, María José. 2015. «La prosa breve de Salvador Rueda». Analecta Malacitana Electrónica 39: 45-71.

Cabrerizo García, María José. 2016. Cuadros de costumbres, cuentos y prosa artística en la obra de Salvador Rueda. Un acercamiento teórico e historiográfico. Granada: Universidad. http://hdl.handle.net/10481/42977

Casas, Ana. 2008. «Los relatos de Salvador Rueda: del cuadro de costumbres al cuento literario». En Salvador Rueda y su época. Autores, géneros y tendencias, ed. Salvador Montesa, 351-362. Málaga: Publicaciones Congreso Literatura Española Contemporánea.

Castillo, Santiago J. 1975. «La prensa diaria de Madrid: notas para el análisis de las estadísticas del timbre (1873-1887)». En Prensa y sociedad en España (1820-1936), ed. Manuel Tuñón de Lara, Antonio Elorza y Manuel Pérez Ledesma, 149-198. Madrid: Edicusa.

Cores Trasmonte, Baldomero. 2009. Alfredo Vicenti. Vida y obra de un gran periodista. Madrid: Asociación de la Prensa de Madrid.

Cortón, Antonio. 1910. «Alfredo Vicenti. (Del tiempo lejano)». El Heraldo de Madrid, 23 mayo: 1 .

Cuevas, Cristóbal. 1986. «Ensayo introductorio». En Canciones y poemas. Antología concordada de su obra poética, XIX-CLI. Madrid: Fundación Ramón Areces.

El Caballero Audaz. 1918. «Nuestras visitas. Salvador Rueda». La Esfera, 26 octubre: 8-9.

Ezama Gil, Ángeles. 1992. El cuento de la prensa y otros cuentos. Aproximación al estudio del relato breve entre 1890 y 1900. Zaragoza: Universidad de Zaragoza.

Freire, Ana María. 2015. «Emilia Pardo Bazán en El Globo». En Emilia Pardo Bazán, periodista, ed. M. ${ }^{\mathrm{a}}$ del Pilar Palomo Vázquez, Pilar Vega Rodríguez y Concepción Núñez Rey, 45-61. Madrid: Arco/Libros.

Gil Muñiz, Antonio. 1957. Salvador Rueda: su vida y su obra. Málaga: edición del autor.

Gómez Aparicio, Pedro. 1971. Historia del periodismo español. De la Revolución de Septiembre al desastre colonial. Madrid: Editora Nacional. 
Isado Jiménez, Pedro J. 1992. Salvador Rueda, poeta modernista. (Recensión de tesis doctoral). Ciudad Real: Pedro J. Isado Jiménez.

Jiménez Morales, María Isabel. 1997. «Prólogo» a Salvador Rueda. En El gusano de luz. Novela andaluza, 13-61. Málaga: Arguval.

Jiménez Morales, María Isabel. 2008. «Las novelas andaluzas de Salvador Rueda (18891892)». En Salvador Rueda y su época. Autores, géneros y tendencias, ed. Salvador Montesa, 149-183. Málaga: Publicaciones Congreso Literatura Española Contemporánea.

Jiménez Morales, María Isabel. 2016. «Edición, introducción y notas». Salvador Rueda. Obras completas. Cuentos y artículos de costumbres, 5-78. Málaga: Universidad de Málaga.

Jiménez Morales, María Isabel. 2017. Los relatos de Salvador Rueda. Sevilla: Renacimiento. Jiménez Morales, María Isabel. 2019. «Inicios literarios de Salvador Rueda en Madrid (18821885)». Epos. Revista de Filología 35: 129-139. https://doi.org/10.5944/epos.35.2019.23072

Jiménez Morales, María Isabel y Amparo Quiles Faz. 2013. «Salvador Rueda». Biblioteca Virtual Miguel de Cervantes. http://www.cervantesvirtual.com/portales/salvador_rueda/

Martínez Olmedilla, Augusto. 1908. Salvador Rueda. Su significación, su vida, sus obras. Madrid: Gregorio Pueyo, Editor.

Niemeyer, Katharina. 1992. La poesía del premodernismo español. Madrid: CSIC.

Orlando. 1885. «Revista literaria. La lírica en este año» [sobre Poema nacional. Costumbres populares]. Revista de España CVI: 295-296.

Ors, Miguel d'. 1973. La sinfonía del año de Salvador Rueda. Pamplona: Eunsa.

Ossorio y Bernard, Manuel. 1908. Ensayo de un catálogo de periodistas españoles del siglo XIX. Madrid: Imp. y Lit. de J. Palacios.

Pappas, Theodore Luke. 1970. Breve biografia de Salvador Rueda con sus cartas inéditas dirigidas a su primo. Charleston: The Citadel, The Military College of South Carolina.

Prados y López, Manuel. 1941. Salvador Rueda, el poeta de la raza. (Su vida y su obra). Málaga: Imprenta Zambrana.

Prados y López, Manuel. 1967. El poeta de la raza. Salvador Rueda renovador de la métrica (ensayo crítico-biográfico). Málaga: Diputación Provincial.

Quiles Faz, Amparo. 1996. Epistolario de Salvador Rueda. 1. Ciento treinta y una cartas autógrafas del poeta (1880-1932). Málaga: Arguval.

Quiles Faz, Amparo. 2005. «Dos cartas de Clarín a Rueda (1888 y 1890)». En A zaga de tu huella. Homenaje al profesor Cristóbal Cuevas, coord. Salvador Montesa Peydró, vol. II, 51-61. Málaga: AEDILE.

Quiles Faz, Amparo. 2006. «De Benaque a Grecia: Salvador Rueda y la Antigüedad clásica». En La tradición clásica en Málaga (siglos XVI-XXI). III Congreso de Historia Antigua de Málaga, ed. Fernando Wulff Alonso, Rafael Chenoll Alfaro e Isabel Pérez López, 279-295. Málaga: Cedma.

Rodríguez Fischer, Ana. 2008. «El colorista malagueño Salvador Rueda: Granada y Sevilla. Bajo-relieves a la pluma (1890)». En Salvador Rueda y su época. Autores, géneros y tendencias, ed. Salvador Montesa, 379-392. Málaga: Publicaciones Congreso Literatura Española Contemporánea.

Rubio Jiménez, Jesús y Antonio Deaño Gamallo. 2014. Vivir de la pluma: 24 cartas inéditas de Salvador Rueda y Rubén Dario a Leopoldo Alas «Clarin». Alicante: Biblioteca Virtual Miguel de Cervantes. http://www.cervantesvirtual.com/nd/ark:/59851/bmcp57f5

Ruiz de Almodóvar, Gabriel. 1891. Salvador Rueda y sus obras. Madrid: Tip. de Manuel Ginés Hernández.

Sánchez Reyes, Enrique. 1957. «Salvador Rueda». Boletín de la Biblioteca Menéndez Pelayo XXXIII, 1-2: 188-207. 
Sancho, Manuel. 1889. Crónica de la coronación de Zorrilla. Granada: Imp. de J. G. Garrido.

Tamayo, Juan Antonio. 1943. «Salvador Rueda o el ritmo». Cuadernos de Literatura Contemporánea 7: 3-35.

Timoteo Álvarez, Jesús. 1981. Restauración y prensa de masas. Los engranajes de un sistema (1875-1883). Pamplona: Eunsa.

Vázquez Otero, Diego. 1960. Salvador Rueda. Málaga: Gráficas Reunidas.

Fecha de recepción: 23 de enero de 2019.

Fecha de aceptación: 12 de junio de 2019. 